\title{
Performance Characterization of Gas-Solid Cyclone for Separation of Particle from Syngas Produced from Food Waste Gasifier Plant
}

\author{
Osezua O. Ibhadode ${ }^{1}$, Emmanuel O.B. Ogedengbe ${ }^{*}$, Marc A. Rosen ${ }^{2}$
}

1 University of Lagos, Nigeria

${ }^{2}$ University of Ontario Institute of Technology, Canada

*Corresponding Author: ogedengbe@energhx.com

Citation: Ibhadode, O.O., Ogedengbe, E.O.B. and Rosen, M.A. (2017). Performance Characterization of GasSolid Cyclone for Separation of Particle from Syngas Produced from Food Waste Gasifier Plant. European Journal of Sustainable Development Research, 1(2), 13.

doi: $10.20897 /$ ejosdr.201713

Published: June 30, 2017

\section{ABSTRACT}

A biofuel from any biodegradable formation process such as a food waste bio-digester plant is a mixture of several gases such as methane $\left(\mathrm{CH}_{4}\right)$, carbon dioxide $\left(\mathrm{CO}_{2}\right)$, hydrogen sulfide $\left(\mathrm{H}_{2} \mathrm{~S}\right)$, ammonia $\left(\mathrm{NH}_{3}\right)$ and impurities like water and dust particles. The results are reported of a parametric study of the process of separation of methane, which is the most important gas in the mixture and usable as a biofuel, from particles and $\mathrm{H}_{2} \mathrm{~S}$. A cyclone, which is a conventional, economic and simple device for gas-solid separation, is considered based on the modification of three Texas A\&M cyclone designs (1D2D, 2D2D and 1D3D) by the inclusion of an air inlet tube. A parametric sizing is performed of the cyclone for biogas purification, accounting for the separation of hydrogen sulfide $\left(\mathrm{H}_{2} \mathrm{~S}\right)$ and dust particles from the biofuel. The stochiometric oxidation of $\mathrm{H}_{2} \mathrm{~S}$ to form elemental sulphur is considered a useful cyclone design criterion. The proposed design includes geometric parameters and several criteria for quantifying the performance of cyclone separators such as the Lapple Model for minimum particle diameter collected, collection efficiency and pressure drop. For biogas volumetric flow rates between 0 and $1 \mathrm{~m} / \mathrm{s}$ and inlet flow velocities of $12 \mathrm{~m} / \mathrm{s}, 15 \mathrm{~m} / \mathrm{s}$ and $18 \mathrm{~m} / \mathrm{s}$ for the 1D2D, 2D2D and 1D3D cyclones, respectively, it is observed that the 2D2D configuration is most economic in terms of sizing (total height and diameter of cyclone). The 1D2D configuration experiences the lowest pressure drop. A design algorithm coupled with a user-friendly graphics interface is developed on the MATLAB platform, providing a tool for sizing and designing suitable cyclones.

Keywords: bibliotherapy, literature and picture books, mathematics confidence, STEM

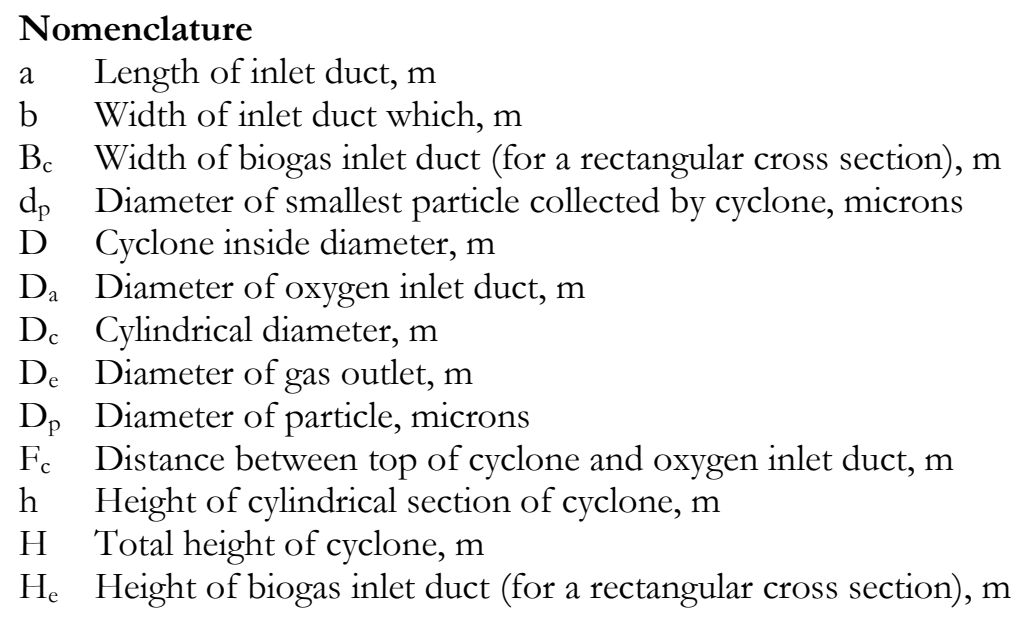


$\mathrm{J}_{\mathrm{e}} \quad$ Diameter of solid particle outlet, $\mathrm{m}$

$\mathrm{L}_{c} \quad$ Length of cylindrical section, $\mathrm{m}$

$\mathrm{S}_{\mathrm{c}} \quad$ Distance between inlet duct and bottom of cylindrical gas outlet device, $\mathrm{m}$

Q Volumetric flow rate of biogas, $\mathrm{m}^{3} / \mathrm{s}$

$V_{\text {in }}$ Inlet velocity of biogas, $\mathrm{m} / \mathrm{s}$

$\mathrm{Z}_{\mathrm{c}} \quad$ Vertical axis length of conical section, $\mathrm{m}$

\author{
Greek Symbols \\ $\rho_{g} \quad$ Gas density $\left(\mathrm{kg} / \mathrm{m}^{3}\right)$ \\ $\rho_{p} \quad$ Particle density $\left(\mathrm{kg} / \mathrm{m}^{3}\right)$ \\ $\mu \quad$ Gas dynamic viscosity $(\mathrm{kg} / \mathrm{m}-\mathrm{s})$
}

\title{
INTRODUCTION
}

Processes for biogas production can be effectively enhanced by encouraging the development of biogas plants that make use of biological wastes. The interest being given to biogas as a renewable energy resource is in part due to its peculiar features, which differ from those for other renewables like wind and solar energy. Apart from the fact that biogas has a fixed energy content (once the composition of the feedstock is known), its potential utilization is mainly independent of factors like geographical location and season, and it is easy to store. Moreover, biogas, and especially bio-methane, can be used directly for heating and electricity generation; or as a substitute for fossil fuels in applications like transportation and power generation (Galante et al., 2012).

Biological wastes include human, animal, plant, and food wastes. Among other sources of biomass, biodegradable material from food waste consists of food scraps from restaurants, produce markets, fish markets, school cafeterias, homes, etc. (Babarinsa et al., 2014). Efforts have been reported on the development of methods for purification and conversion of raw biogas to a processed fuel, bio-methane, which has the potential, according to its properties, to replace natural gas. The intensity of these efforts is mainly influenced by increases in fossil fuel prices and their gradual scarcity, as well as environmental concerns (Fodora et al., 2013).

Figure 1 shows a schematic of a concentrated solar power (CSP)-driven gasifier. This device is an assembly of subsystems: solar micro-collector, downdraft gasifier, feedstock collector/homogenizer, and methane synthesizer. Such a system has been applied in a university cafeteria (Ogedengbe and Rosen, 2012). In this methane production plant, heat is transferred from the solar micro-collector for use in subsystems like the downdraft gasifier and the feedstock collector/homogenizer. The food waste is fed into the gasifier as a moisture-rich liquid, known as a slurry. This process requires the design of a thermally controlled storage and homogenizing subsystem, where the time lag between food waste collection and its digestion is automated (Ogedengbe and Rosen, 2012). The production of methane depends on the capacities of the methane synthesizer and the gasifier subsystems, which are designed based on the estimated supply of food waste (Ogedengbe and Rosen, 2012). The methane synthesis stage is where purification processes are required. Among other processes, purification of the $\mathrm{H}_{2} \mathrm{~S}$ - and particlerich biofuel is an important requirement within methane synthesis. This need is addressed in this article.

Typical biogas has an approximate volumetric composition of 45-65\% methane $\left(\mathrm{CH}_{4}\right), 30-40 \%$ carbon dioxide $\left(\mathrm{CO}_{2}\right), 0-5 \%$ nitrogen $\left(\mathrm{N}_{2}\right), 0-2 \%$ oxygen $\left(\mathrm{O}_{2}\right), 0.3-3 \%$ hydrogen sulfide $\left(\mathrm{H}_{2} \mathrm{~S}\right), 0-10 \%$ moisture $\left(\mathrm{H}_{2} \mathrm{O}\right), 0-1 \%$ hydrogen, and $0-1 \%$ ammonia $\left(\mathrm{NH}_{3}\right)$ (Urya Bio-Systems, 2015). Methane and carbon dioxide are the main constituents of biogases, and the others are basically impurities. Possible impacts of the impurities are shown in Table 1.

For biogas purification and conversion, various methods based on the adsorption, absorption, chemical and biological principles are used. The most commonly used technology for biogas purification is the water scrubber, which involves absorption of $\mathrm{CO}_{2}$ and $\mathrm{H}_{2} \mathrm{~S}$ by the liquid medium, water, at a pressure of $1000 \mathrm{kPa}$ (Fodora et al., 2013). Other common purification methods include adsorption during pressure change (pressure swing adsorption), during temperature change (temperature swing adsorption) and at vacuum conditions (vacuum swing adsorption). Less known processes for raising the methane content in a biogas are membrane and cryogenic separation and biological methods (Fodora et al., 2013); these processes are economically and technically demanding.

The raw biogas contains impurities (e.g., water, dust, $\mathrm{H}_{2} \mathrm{~S}, \mathrm{CO}_{2}$, siloxanes, hydrocarbons, $\mathrm{NH}_{3}$, oxygen) that must be removed in order to reach certain quality standards (Galante et al., 2012). Hydrogen sulfide is a colorless, poisonous and flammable gas. It has the odor of rotten eggs, mainly from the bacterial breakdown of organic matter in the absence of oxygen, such as in swamps and sewers. This anaerobic digestion is the main process in biogas formation (Galante et al., 2012). A cost effective and technically straightforward physical separation method to purify biogas by removing hydrogen sulfide and dust particles involves the addition of oxygen/air in a cyclone 


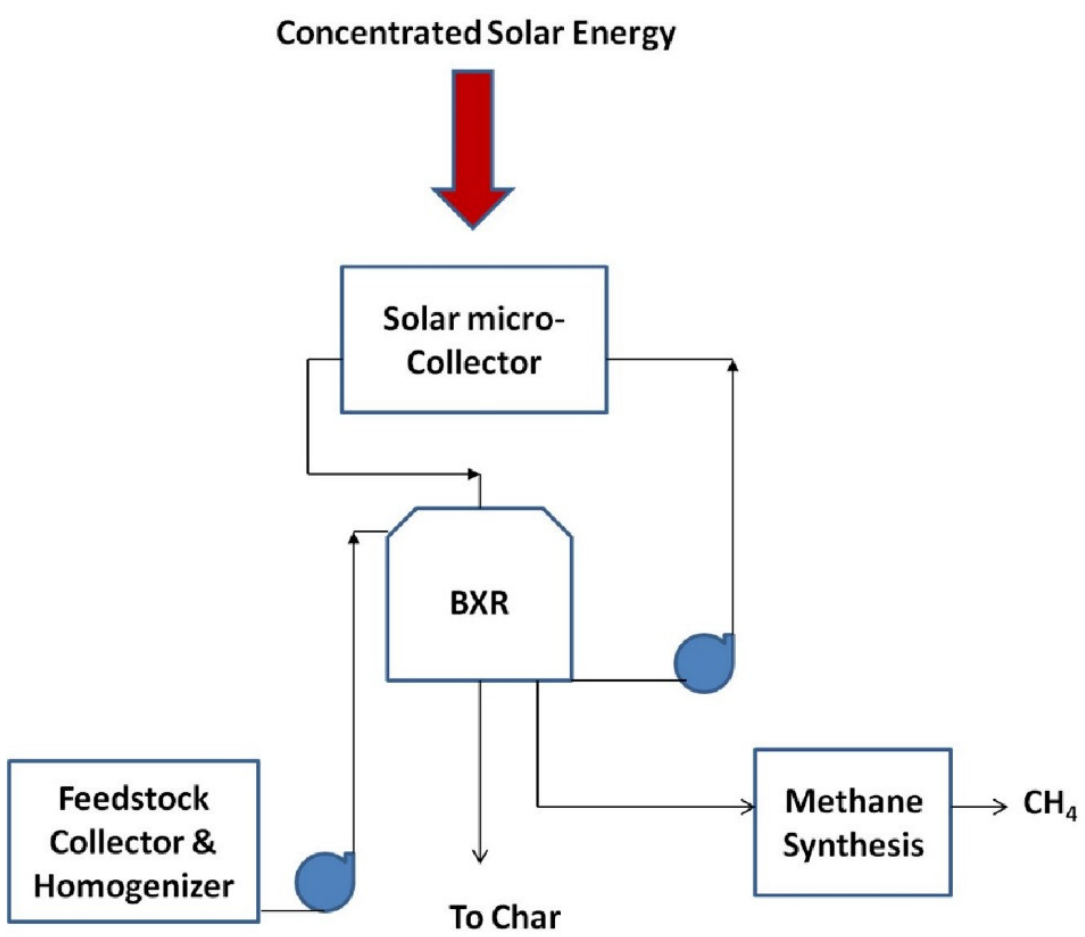

Figure 1. Hybrid model of continuity and availability management.

Table 1. Biogas impurities and their consequences (source: (Galante et al., 2012)).

\begin{tabular}{|c|c|}
\hline Impurity & Possible Impact \\
\hline Water & $\begin{array}{l}\text { Corrosion in compressors, gas storage tanks and engines due to reactions with } \mathrm{H} 2 \mathrm{~S} \text {, } \\
\mathrm{NH} 3 \text { and } \mathrm{CO} 2 \text { to form acids } \\
\text { Accumulation of water in pipes } \\
\text { Condensation and/or freezing due to high pressure }\end{array}$ \\
\hline Dust & Clogging due to deposition in compressors, gas storage tanks \\
\hline $\mathrm{H} 2 \mathrm{~S}$ & $\begin{array}{l}\text { Corrosion in compressors, gas storage tanks and engines } \\
\text { Toxic concentrations of } \mathrm{H} 2 \mathrm{~S}(>5 \mathrm{~cm} 3 \mathrm{~m}-3) \text { remain in the biogas } \\
\mathrm{SO} 2 \text { and SO3 formation due to combustion (these are more toxic than } \mathrm{H} 2 \mathrm{~S} \text { and } \\
\text { cause corrosion with water) }\end{array}$ \\
\hline $\mathrm{CO} 2$ & Low calorific value \\
\hline Siloxanes & $\begin{array}{l}\text { Formation of } \mathrm{SiO} 2 \text { and microcrystalline quartz due to combustion, followed by } \\
\text { deposition at spark plugs, valves and cylinder heads, abrading the surface }\end{array}$ \\
\hline Hydrocarbons & Corrosion in engines due to combustion \\
\hline $\mathrm{NH} 3$ & Corrosion when dissolved in water \\
\hline $\mathrm{O} 2 /$ air & Explosive mixtures due to high concentrations of $\mathrm{O} 2$ in biogas \\
\hline $\mathrm{Cl}-$ & Corrosion in combustion engines \\
\hline Fl- & Corrosion in combustion engines \\
\hline
\end{tabular}

separator. A cyclone is a simple dust control device with low manufacturing and operating costs, and it is easy to maintain. It can be used to handle high temperature and high pressure exhaust gas (Kuo and Tsai, 2001). Small cyclones are used to collect particles in the field of air pollution control for ambient sampling, while large cyclones are used to remove particles from industrial gas streams (Kim et al., 2001). The incoming oxygen reacts with $\mathrm{H}_{2} \mathrm{~S}$ in the biogas and forms water and elemental sulfur. The main chemical reaction is as follows:

$$
2 \mathrm{H}_{2} \mathrm{~S}+\mathrm{O}_{2} \rightarrow 2 \mathrm{~S}+2 \mathrm{H}_{2} \mathrm{O}
$$

To promote the chemical reaction, catalysts are usually introduced in the form of micro-organisms; desulphurization acts as a source of energy for their metabolism. This action is taken in the presence of oxygen, and the oxygen availability should be about $6-12 \%$ of the biogas volume (Fodora et al., 2013). The cyclone can be inoculated by introducing a cultured bacteria, as in the cyclone separator developed by Fodora et al. (2013). 

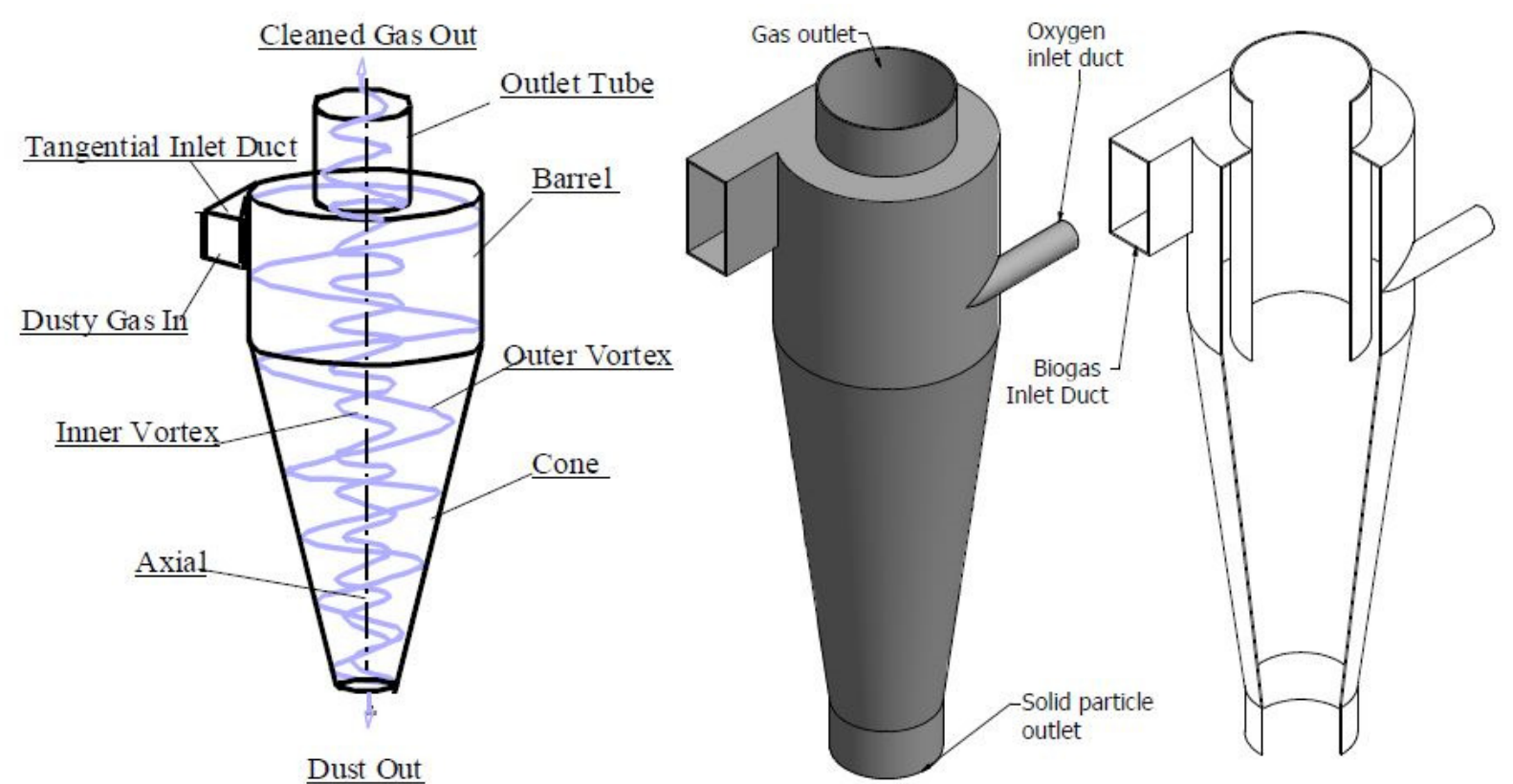

Dust Out

Figure 2. Flow diagram of a conventional cyclone (Wang, 2004), and the modified cyclone design with oxygen inlet duct.

In this work, a parametric study showing how input and operational parameters affect cyclone sizing and performance is performed on the sizing of a separator that purifies biogas by removing hydrogen sulfide through a cost effective and simple cyclone device. The proposed operation involves a chemical reaction that produces elemental sulfur to permit the physical separation of the sulfur particles from biogas. The cyclone separator design provides the appropriate mixture of both gaseous phase constituents (biogas and atmospheric oxygen). The rotary motion of the gaseous components in the separator suitably mixes of the gases so as to provide a more complete chemical reaction of hydrogen sulfide with oxygen, while accommodating the degradation of hydrogen sulfide to elemental sulfur (Fodora et al., 2013).

\section{SEPARATOR DESIGN ALGORITHM}

The gas cyclone is a flow device in which the inlet gas tangentially enters a cylindrical body. A strong vortex is created within the cyclone, whereby any particle in the flow, if they are denser than the carrier gas, are subject to centrifugal forces. The particles consequently move radially outwards, and are deposited on the inside cyclone surface (Svarovsky, 2014). The design of the gas cyclones developed here is based on a modification of the Texas A\&M Cyclone Design (TCD) (Wang, 2004). The TCD configurations are 1D3D, 2D2D and 1D2D; where the first numeral is a multiple of $\mathrm{D}$ (cylindrical diameter) which designates the length of the cylindrical section and the second numeral, also a multiple of $\mathrm{D}$ designates the vertical length of the conic section. This modification provides an air inlet to permit the chemical reaction of hydrogen sulfide $\left(\mathrm{H}_{2} \mathrm{~S}\right)$ in the biogas and oxygen $\left(\mathrm{O}_{2}\right)$ in the air. A significant charateristic of the TCD approach is the determination of the optimum inlet velocities (design velocities) that are suitable for different cyclone designs. The design inlet velocities for 1D3D, 2D2D, and 1D2D cyclones are $16 \mathrm{~m} / \mathrm{s} \pm 2 \mathrm{~m} / \mathrm{s}(3200 \mathrm{ft} / \mathrm{min} \pm 400 \mathrm{ft} / \mathrm{min}), 15 \mathrm{~m} / \mathrm{s} \pm 2 \mathrm{~m} / \mathrm{s}(3000 \mathrm{ft} / \mathrm{min} \pm 400 \mathrm{ft} / \mathrm{min})$, and $12 \mathrm{~m} / \mathrm{s} \pm 2$ $\mathrm{m} / \mathrm{s}(2400 \mathrm{ft} / \mathrm{min} \pm 400 \mathrm{ft} / \mathrm{min}$ ), respectively (Wang, 2004). This approach allows the engineer to design the cyclone using an inlet velocity specific to the type of cyclone desired (Wang, 2004). A conventional cyclone separator is shown in Figure 2.

The modified cyclone used here for hydrogen sulfide and dust removal has an inlet duct for air or oxygen. This is important for the chemical reaction between $\mathrm{H}_{2} \mathrm{~S}$ and $\mathrm{O}_{2}$, where oxygen of 6-12\% of biogas by volume is required for the reaction. The modified design is shown in Figure 2 and the orthographic projection in Figure 3.

The following design process is necessary for characterization of a typical cyclone separator:

1. Determination of barrel/cylindrical drum diameter, $\mathrm{D}$ : The characteristic velocity, $\mathrm{V}$ can be defined for gas cyclones in various ways but the simplest definition as proposed by Svarovsky (2014) is based on the crosssection of the cylindrical body of the cyclone. In this case,

$$
V_{\text {in }}=\frac{4 Q}{\pi D^{2}}
$$




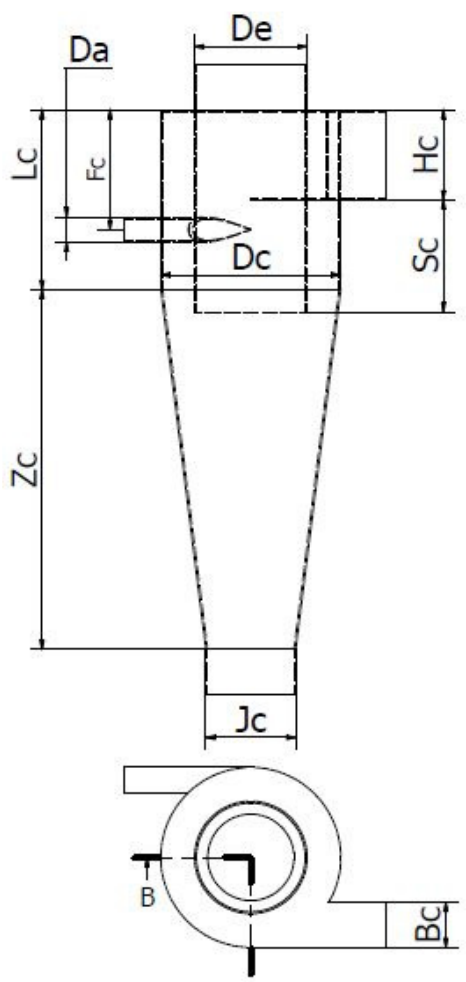

Figure 3. Orthographic view of cyclone design.

Rearranging, we find

$D=\sqrt{\frac{4 Q}{\pi V_{\text {in }}}}$

Wang et al. (2004) point out that cyclone size and configuration depend on the cyclone design velocity and the volume of air handled. The barrel or cylindrical diameter of 1D2D, 2D2D and 1D3D cyclone configurations can be sized as follows (Wang, 2004):

$D_{c}=\sqrt{\frac{8 Q}{V_{i n}}}$

2. Determination of cyclone configuration and geometric parameters: Cyclone designs are described by relating the height of the cylinder and cone sections to the cylinder diameter (Funk and Baker, 2013).

a. For inlet velocities of $12 \mathrm{~m} / \mathrm{s} \pm 2 \mathrm{~m} / \mathrm{s}$, the optimum configuration is $1 \mathrm{D} 2 \mathrm{D}$ and geometric parameters are obtainable as follows:

$$
B_{C}=\frac{D_{c}}{4}, D_{e}=\frac{D_{c}}{1.6}, H_{C}=\frac{D_{C}}{2}, J_{C}=\frac{D_{C}}{2}, S_{C}=\frac{5 D_{C}}{8} ; L_{C}=D_{c}, Z_{C}=2 D_{c}
$$

b. For inlet velocities of $15 \mathrm{~m} / \mathrm{s} \pm 2 \mathrm{~m} / \mathrm{s}$, the optimum configuration is $2 \mathrm{D} 2 \mathrm{D}$ and geometric parameters are obtainable as follows:

$B_{C}=\frac{D_{c}}{4}, D_{e}=\frac{D_{c}}{2}, H_{C}=\frac{D_{C}}{2}, J_{C}=\frac{D_{C}}{4}, S_{C}=\frac{D_{C}}{8} ; L_{C}=2 D_{c}, Z_{C}=2 D_{c}$

c. For inlet velocities of $16 \mathrm{~m} / \mathrm{s} \pm 2 \mathrm{~m} / \mathrm{s}$, the optimum configuration is $1 \mathrm{D} 3 \mathrm{D}$ and geometric parameters are obtainable as follows:

$B_{C}=\frac{D_{c}}{4}, D_{e}=\frac{D_{c}}{2}, H_{C}=\frac{D_{C}}{2}, J_{C}=\frac{D_{C}}{4}, S_{C}=\frac{D_{C}}{8} ; L_{C}=D_{c}, Z_{C}=3 D_{c}$

3. Determination of oxygen inlet duct diameter: In many cases, the inlet to a cyclone is of a rectangular cross section. Inlets with circular cross sections ('pipe-type' inlets) are mainly used in small sampling cyclones, and in applications where a simple circular inlet achieves the desired separation while providing construction simplicity and low cost (Hoffmn et al., 2002). For the present design, the biogas inlet is rectangular in cross 


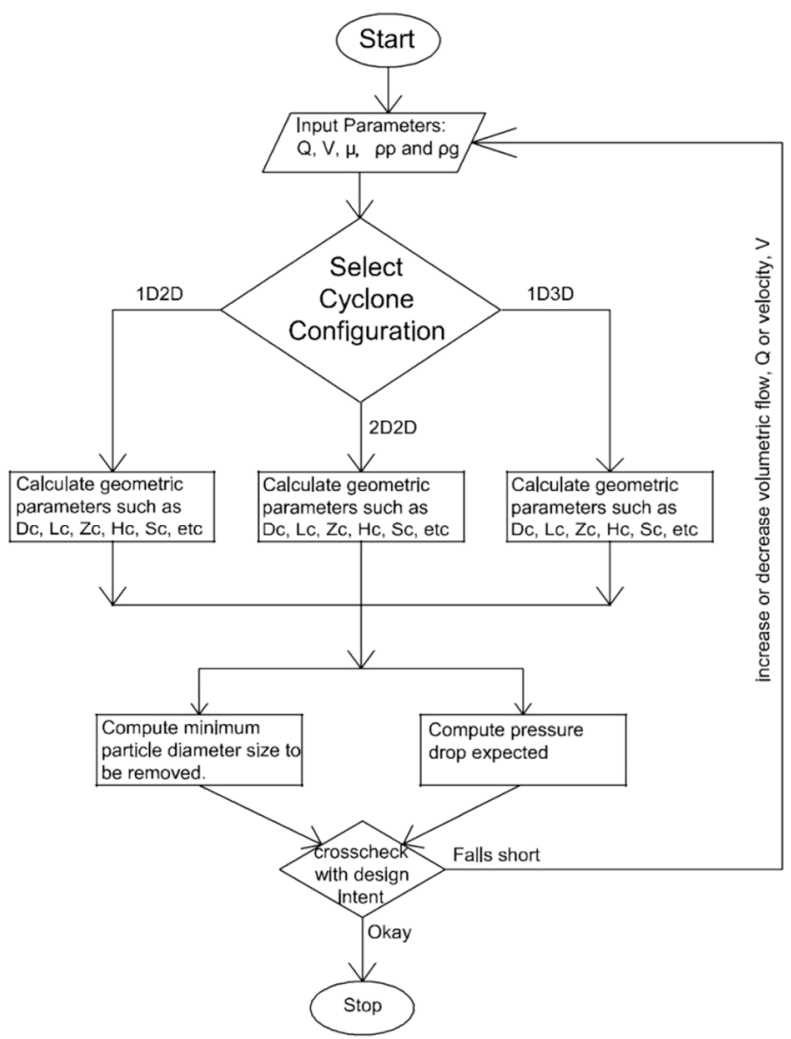

Figure 4. Design algorithm of a cyclonic separator for removal of sulfur particles in biogas purification.

section, but the oxygen inlet cross section is circular with an area of approximately $6-12 \%$ of the biogas inlet cross sectional area. Using the higher of these values, we can write:

Cross sectional area of circular duct for oxygen $=12 \%$ of biogas inlet cross sectional area or

$$
\frac{\pi D_{a}^{2}}{4}=0.12 \times B_{c} \times H_{c}
$$

Solving for $\mathrm{D}_{\mathrm{a}}$ yields

$$
D_{a}=\sqrt{\frac{0.12 \times B_{c} \times H_{c}}{\pi}}
$$

Also, Fc is given by a fraction of the cyclone diameter similar to that proposed by Fodora et al. (2013):

$$
\mathrm{F}_{\mathrm{c}}=\frac{2}{3} \mathrm{D}_{\mathrm{c}}
$$

The design algorithm is developed to select and size cyclones based on the application conditions, such as the volumetric flow rate, velocity, and dynamic viscosity of gas. The algorithm is written in the MATLAB programming language. A flow chart for design process is shown in Figure 4.

A Graphics User Interface (GUI) is also designed on the MATLAB platform to make it easier for users to determine the appropriate cyclone configuration and sizing necessary for a particular application, following the modified Texas A\&M design criteria and process. This is achieved by a 'plug and play' input-output feature of the GUI. The input requirement panel contains inputs for the gas properties as well as the volumetric flow rate and velocity; the outputs are the required geometric parameters, the configuration of the cyclone, the estimated minimum diameter as well as the approximate pressure drop expected based on three models. Figure 5 shows the layout of the interface: 


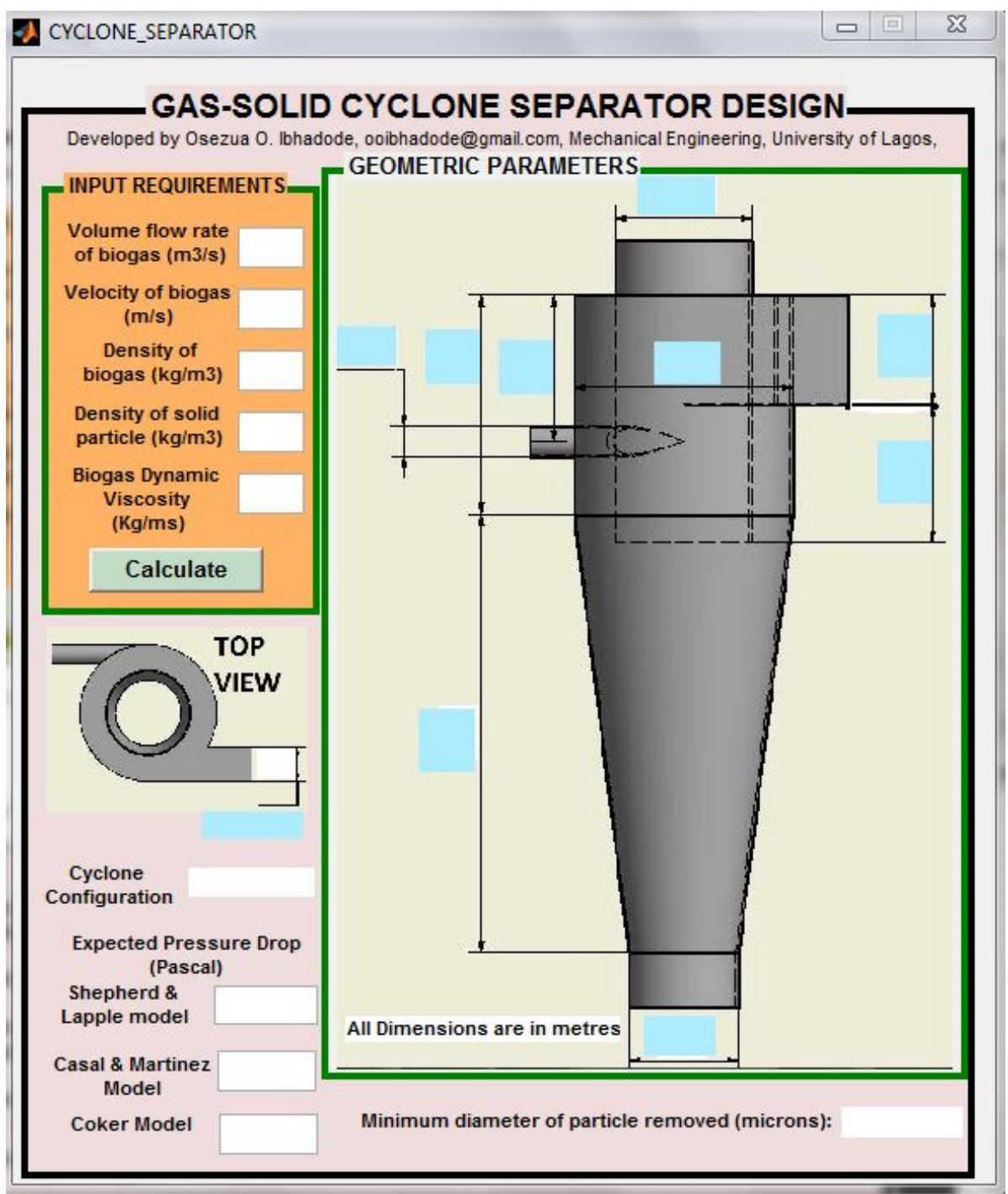

Figure 5. Graphic User Interface for syngas-solid cyclone separator design.

\section{CYCLONE PERFORMANCE}

As earlier established, the reaction between oxygen in air and $\mathrm{H}_{2} \mathrm{~S}$ in biogas yields elemental sulfur as one of the products. It is important to investigate the performance of cyclones in separating these solids from the biogas mixture. The Lapple model for minimum particle diameter collected, collection efficiency, pressure drop models are considered useful criteria in evaluating cyclone performance.

\section{Lapple Model}

Many studies have been made to characterize cyclone performance as affected by design and operational parameters (Wang et al., 2003). The Lapple model is amongst the earliest of models proposed and is still considered the bench mark for the design of cyclone separators in many industries (Pandya, 2010). It assumes that the particles are evenly distributed across the inlet while entering the cyclone. Balanced - forces collection, is the principle behind the Lapple model as well as other early models such as Stairmand model and the combined Shepherd and Lapple model. Balanced - forces or equilibrium-orbit models, assume that collection efficiency (the cut-point) occurs when the drag force acting on the particle's volume surface is just strong enough to hold the particle in a circular orbit. Drag force is caused by gas flow towards the center (Funk and Baker, 2013). The particle will settle if gravitational attraction is greater, and will escape if the drag force caused by rising gasses is greater (Funk and Baker, 2013). The Lapple model is based on the terminal velocity of particles in the cyclone. Depending on the number of turns for the solid particles within the cyclone, the diameter of each of the solid particle is given by (Pandya, 2010): 


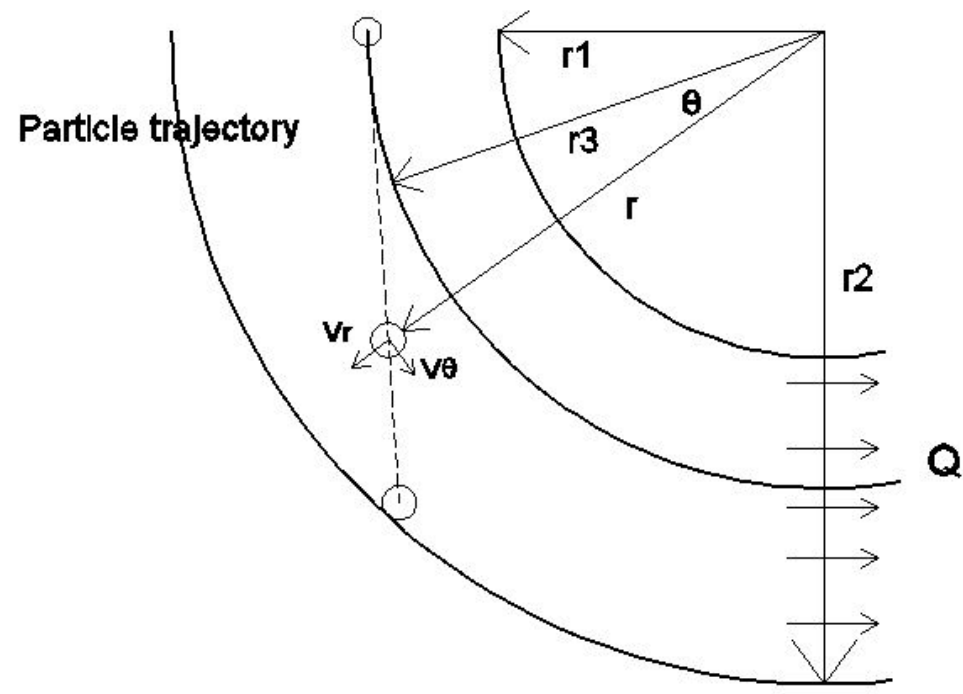

Figure 6. Trajectory of a particle in a laminar cyclonic flow. Adapted from (Benitez, 1993).

$$
d_{p}=\sqrt{\frac{9 \mu b}{\pi N_{e} V_{i n}\left(\rho_{p}-\rho_{g}\right)}}
$$

Where the number of turns for the solid particles follows:

$$
\mathrm{N}_{\mathrm{e}}=\frac{1}{a}\left[h+\frac{H-h}{2}\right]
$$

\section{Cyclone Collection Efficiency}

The cyclone collection efficiency is based on an ideal laminar cyclonic flow, which can also be referred to as a frictionless flow were the streamlines are assumed to follow the contours of the cyclone. Figure 6 describes the trajectory of a particle in a laminar cyclonic flow.

To determine the collection efficiency, a particle is considered to enter the cyclone at a radial position $r_{3}$ that strikes the wall at an angular position $\theta_{\mathrm{f}}$. Benitez (1993) notes that the following differential equation describes the particle's trajectory:

$$
\frac{d \theta}{d r}=\frac{18 \mu a \ln \left(\frac{r_{2}}{r_{1}}\right) r}{\rho_{p} Q D_{p}^{2}}
$$

To obtain an expression for the collection efficiency of the cyclone, it is assumed that the entering particle concentration and gas velocity are uniform across the entrance cross section. If the cyclone has an angle $\theta_{\mathrm{f}}$, all particles that enter the device at $r \geq r_{3}$ hit the wall over $0 \leq \theta \leq \theta_{\mathrm{f}}$. The collection efficiency is simply the fraction of the particles in the entering flow that strike the outer wall before $\theta=\theta_{\mathrm{f}}$ (Benitez, 1993). The expression for collection efficiency is therefore

$$
\eta\left(D_{p}\right)=\frac{1-\left[1-\frac{\rho_{p} Q D_{p}^{2} \theta_{f}}{9 \mu W r_{2}^{2} \ln \left(\frac{r_{2}}{r_{1}}\right)}\right)}{1-r_{1} / r_{2}}
$$

\section{Cyclone Pressure Drop $(\Delta \mathrm{P})$}

The pressure drop in the cyclone is another significant parameter in designing a cyclone system. The TCD process provides the following empirical correlation for cyclone pressure drop (Wang, 2004):

$$
\Delta \mathrm{P}=\mathrm{K} *\left(\mathrm{VP}_{\mathrm{i}}+\mathrm{VP}_{\mathrm{o}}\right)
$$

Where VP denotes velocity pressure of a gas, and $\mathrm{K}$ is a dimensionless empirical constant, which takes on a value of 5.1, 4.7 and 3.4 for 1D3D, 2D2D and 1D2D cyclones, respectively.

An alternative expression for cyclone pressure drop occasionally used in design is (NPTEL, 2015): 


$$
\Delta \mathrm{P}=\frac{0.0027 Q^{2}}{K_{c} D_{c}^{2} B_{c} H_{c}\left(\frac{L_{c}}{D_{c}}\right)^{1 / 3}\left(\frac{Z_{c}}{D_{c}}\right)^{1 / 3}}
$$

Here, $\mathrm{K}_{\mathrm{c}}$ is a dimensionless factor related to cyclone inlet vanes. For cyclones without vanes $\mathrm{K}_{\mathrm{c}}=0.5$, and $\mathrm{K}_{\mathrm{c}}$ $=1.0$ for cyclone vanes that do not expand the entering gas or touch the outer wall while $K_{c}=2.0$ for cyclone vanes that expand and touch the outlet all. The above equation, when compared with experimental data, exhibits a poor correlation coefficient (NPTEL, 2015).

Pandya (2010) lists several empirical models for the pressure drops in cyclone separators. The pressure drop in a cyclone is proportional to velocity head:

$$
\Delta \mathrm{P}=\alpha \frac{\rho V_{i n}}{2},
$$

Various empirical exist models for $\alpha$ (a dimensionless parameter), and these provide different values. Three empirical models by Shepherd and Lapple in 1939, Casal and Martinez in 1983, and Coker in 1993 will be reviewed. In Shepherd and Lapple model (1939), $\alpha$ is obtained as the static pressure drop shown in Eq. 18. For cyclones without any volutes (spiral formation) in the inlet or outlet ducts, $\alpha$ can be estimated more accurately from the Casal and Martinez model (1983), $\alpha$ is derived through statistical analyses of experimental data and given by Eq. 19. Similarly, Coker model (1993), provides an expression for $\alpha$ in Eq. 20.

$$
\begin{aligned}
& \alpha=\frac{16 a b}{D_{e}^{2}} \\
& \alpha=11.3\left(\frac{a b}{D_{e}^{2}}\right)^{2}+3.33 \\
& \alpha=9.47 \frac{a b}{D_{e}^{2}}
\end{aligned}
$$

\section{RESULTS AND DISCUSSION}

According to the various research studies, the performance of the cyclones is influenced considerably by cyclone height, diameter and shape (i.e., cylindrical or rectangular); shape and diameter of the gas outlet (commonly referred as vortex finder); and inlet geometry (Park et al., 2012). Table 2 shows the cyclone working conditions and gas properties considered here. A parametric analysis is performed to determine the effects of biogas inlet velocity (for the three major design configurations) and volumetric flow rate on two key cyclone geometric parameters (total height and diameter). Figures 7 and 8 show the results.

Table 2. Cyclone working conditions and gas properties.

\begin{tabular}{|l|l|}
\hline Parameter & Value(s) \\
\hline Biogas volumetric flow rate & $0-1 \mathrm{~m} 3 / \mathrm{s}$ \\
\hline Gas inlet velocity & $12 \mathrm{~m} / \mathrm{s}$ for 1D2D, 15m/s for 2D2D and $18 \mathrm{~m} / \mathrm{s}$ for 1D3D configurations \\
\hline Biogas density & $1.15 \mathrm{~kg} / \mathrm{m} 3$ \\
\hline Density of elemental sulfur & $1960 \mathrm{~kg} / \mathrm{m} 3$ \\
\hline Dynamic viscosity of biogas & $1.3 \times 10-5 \mathrm{~kg} / \mathrm{m}-\mathrm{s}$ \\
\hline
\end{tabular}




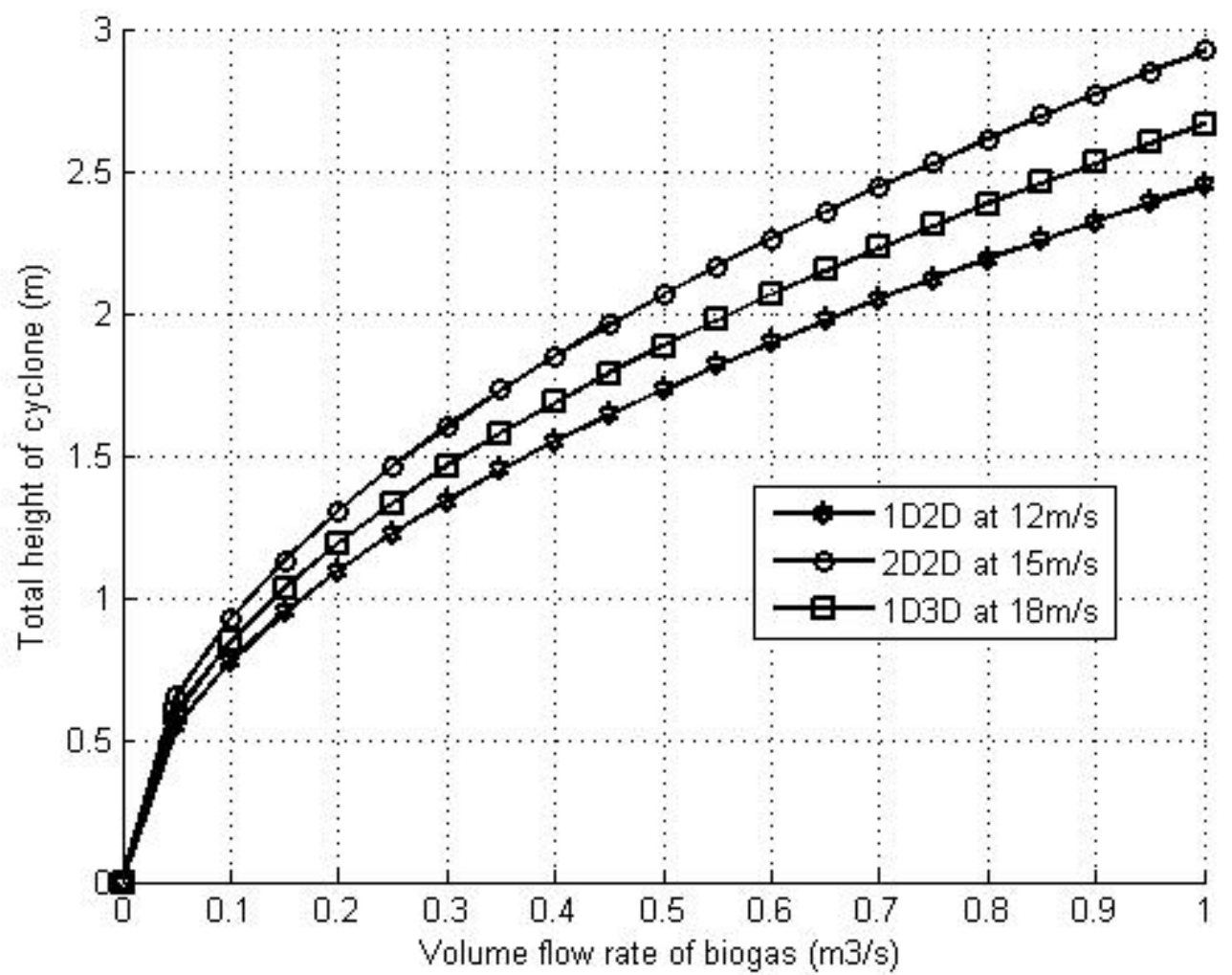

Figure 7. Effect of volumetric flow rate on total height of cyclone for 1D2D, 2D2D and 1D3D configurations.

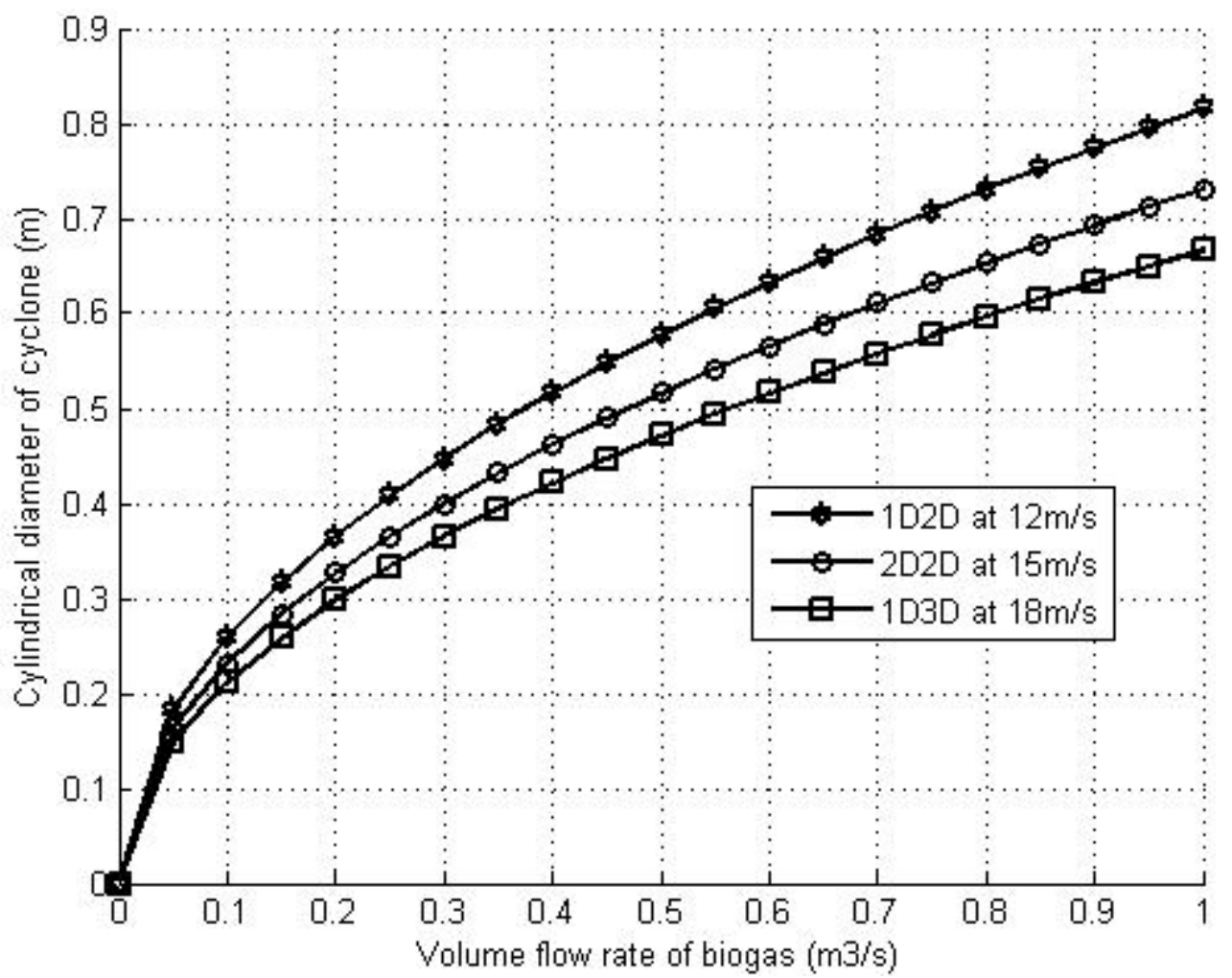

Figure 8. Effect of volumetric flow rate on diameter of cyclone for 1D2D, 2D2D and 1D3D configurations.

It is seen in Figure 7 that the 1D2D configuration has the least cyclone height value compared to the others for any unique volumetric flow rate between 0 and $1 \mathrm{~m} / \mathrm{s}$. In Figure 8, the 1D3D configuration is observed to exhibit the lowest cylindrical diameter for any volumetric flow rate; the 2D2D configuration remains in the middle for both cases. Therefore, regarding economy in geometric design criteria (height and diameter sizing), the 2D2D configuration lies within the others.

The minimum particle diameter $\left(\mathrm{d}_{\mathrm{p}}\right)$ in equation 11 is the size of the smallest particle collected if it starts at the inside edge of the inlet duct. Thus, in theory, all particles of size $d_{p}$ or larger are collected with $100 \%$ efficiency 


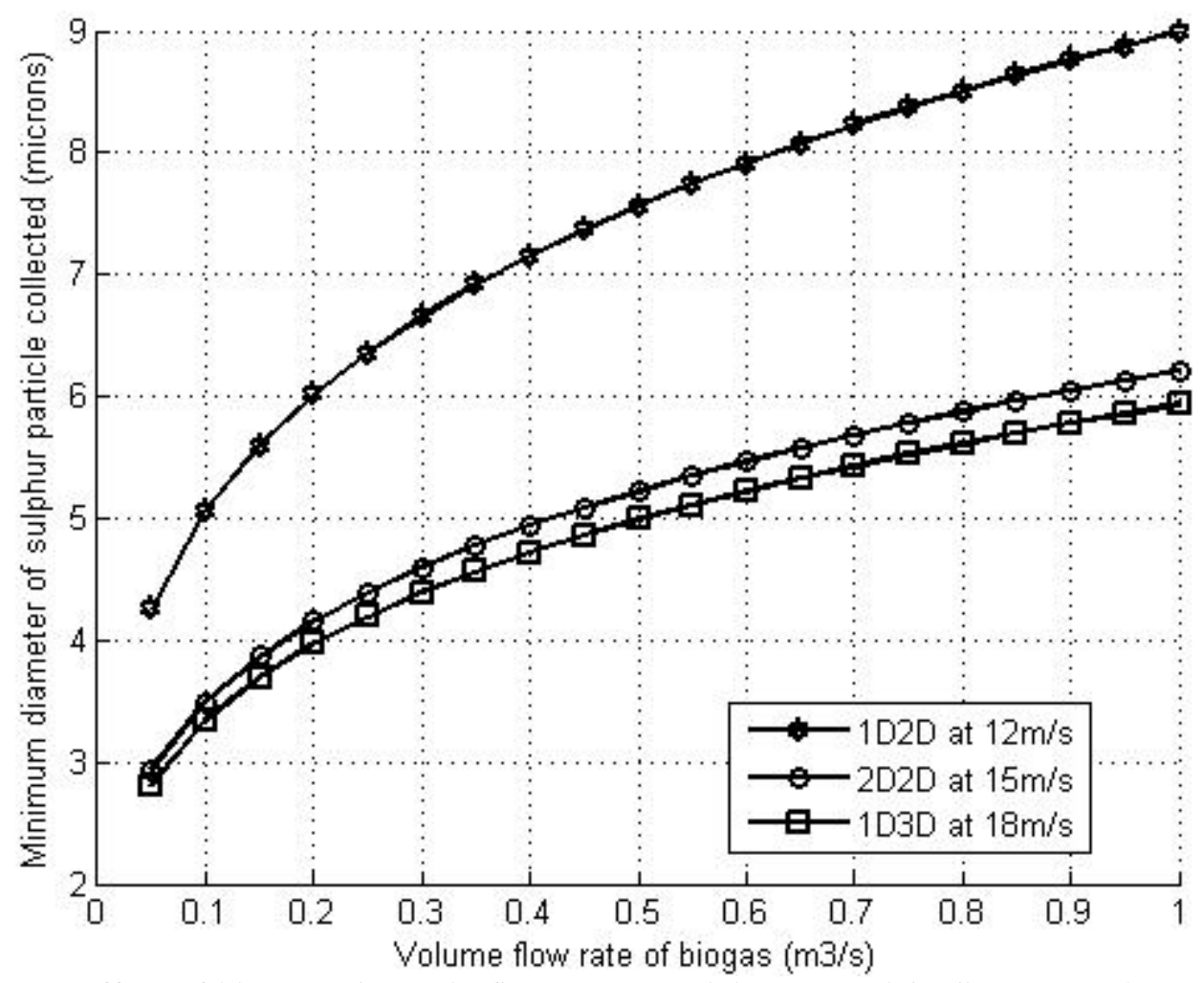

Figure 9. Effect of biogas volumetric flow rate on minimum particle diameter to be collected for 1D2D, 2D2D and 1D3D configurations.

(Nazaroff et al., 2013). Figure 9 shows how changes in volumetric flow rate affect the minimum particle diameter that is removed by the cyclone. The 1D2D configuration is seen to demonstrate the least impressive minimum diameter removal relative to the other configurations at every volumetric flow rate. The 1D3D configuration is shown to have the best particle removal size, closely followed by the 2D2D configuration.

Figure 11 shows the variation of collection efficiency with particle size distribution at a gas entry volumetric flow rate of $0.2 \mathrm{~m}^{3} / \mathrm{s}$ of a cyclone. The collection efficiency plot is closely related to minimum diameter plot in quantifying cyclone performance. The size distribution of each cyclone configuration is taken from 0 to the minimum diameter $\left(d_{p}\right)$ for a $100 \%$ efficiency. The collection efficiency for the $1 \mathrm{D} 3 \mathrm{D}$ configuration is seen to be the greatest, closely followed by 2D2D configuration, in a similar way as for Figure 9.

The pressure drop in a cyclone is an important consideration along with collection efficiency. While forcing a gas through the cyclone at higher velocities results in improved removal efficiencies, doing so also increases the pressure drop and, as a consequence, the operating costs. There is an economic trade-off between efficiency and operating cost (Benitez, 1993). To determine the variation in pressure drop as gas inlet velocity changes, the approaches of Shepherd and Lapple (1939), Casal and Martinez (1983) and Coker (1993) are employed; inlet and gas conditions for the pressure drop investigation are shown in Table 3. In Figure 11, it is observed that the model by Shepherd and Lapple (1939) gives the greatest pressure drop followed by the model of Casal and Martinez (1983). Note that for each model an inlet velocity increase beyond $14 \mathrm{~m} / \mathrm{s}$ leads to a sharp rise in pressure drop. Therefore, cyclones with design inlet velocities greater than $14 \mathrm{~m} / \mathrm{s}$ exhibit much higher pressure drops and operating costs than cyclones with lower inlet velocities.

Table 3. Cyclone conditions, gas and solid properties for pressure drop investigation.

\begin{tabular}{|l|l|}
\hline Parameter & Value(s) \\
\hline Biogas volumetric flow rate & $0.2 \mathrm{~m} 3 / \mathrm{s}$ \\
\hline Gas inlet velocity & $0-18 \mathrm{~m} / \mathrm{s}$ \\
\hline Biogas density & $1.15 \mathrm{~kg} / \mathrm{m} 3$ \\
\hline Density of elemental sulfur & $1960 \mathrm{~kg} / \mathrm{m} 3$ \\
\hline Dynamic viscosity of biogas & $1.3 \times 10-5 \mathrm{~kg} / \mathrm{m}-\mathrm{s}$ \\
\hline
\end{tabular}




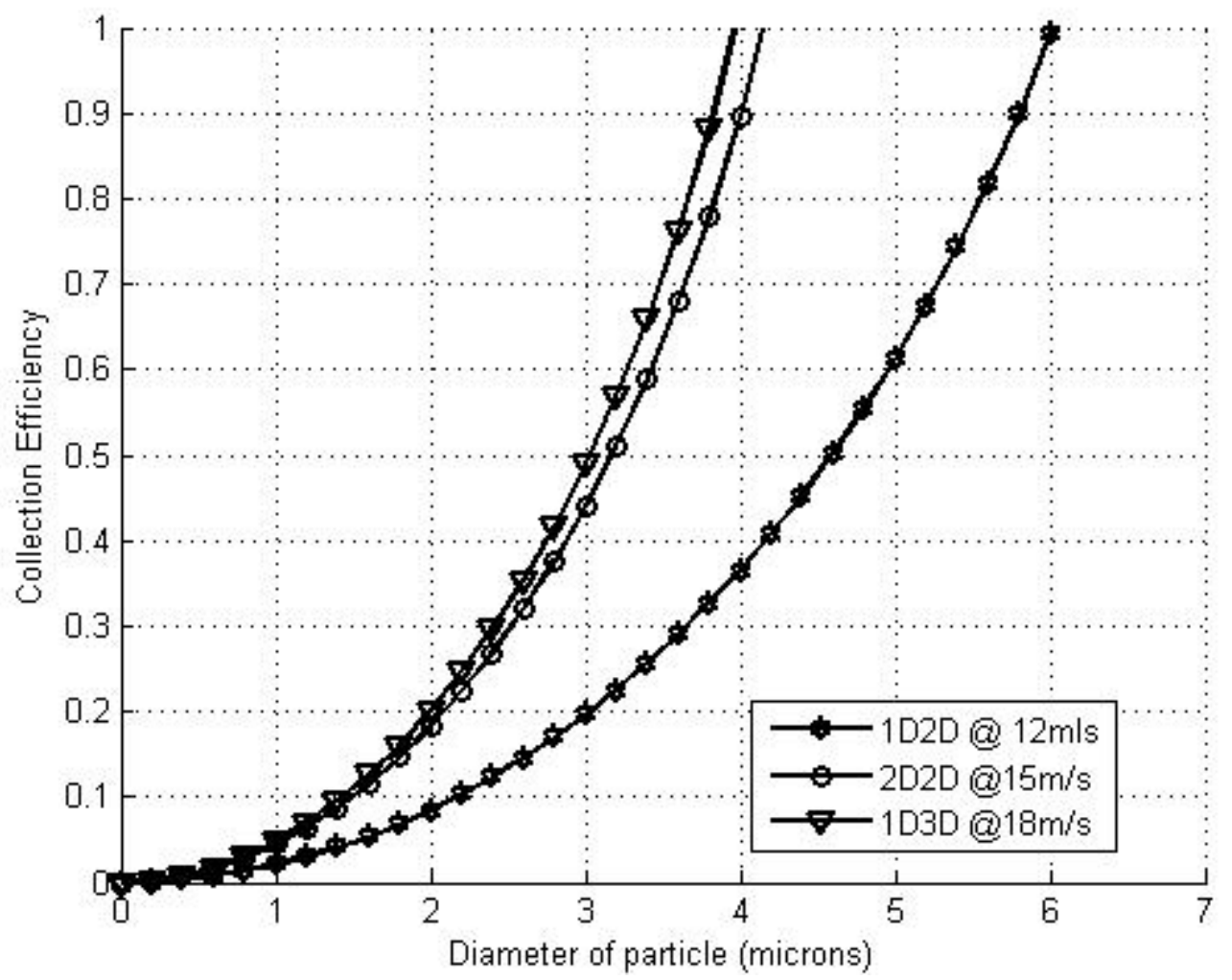

Figure 10. Cyclone collection efficiency for 1D2D, 2D2D and 1D3D configurations at a gas entry volumetric flow rate of $0.2 \mathrm{~m}^{3} / \mathrm{s}$.

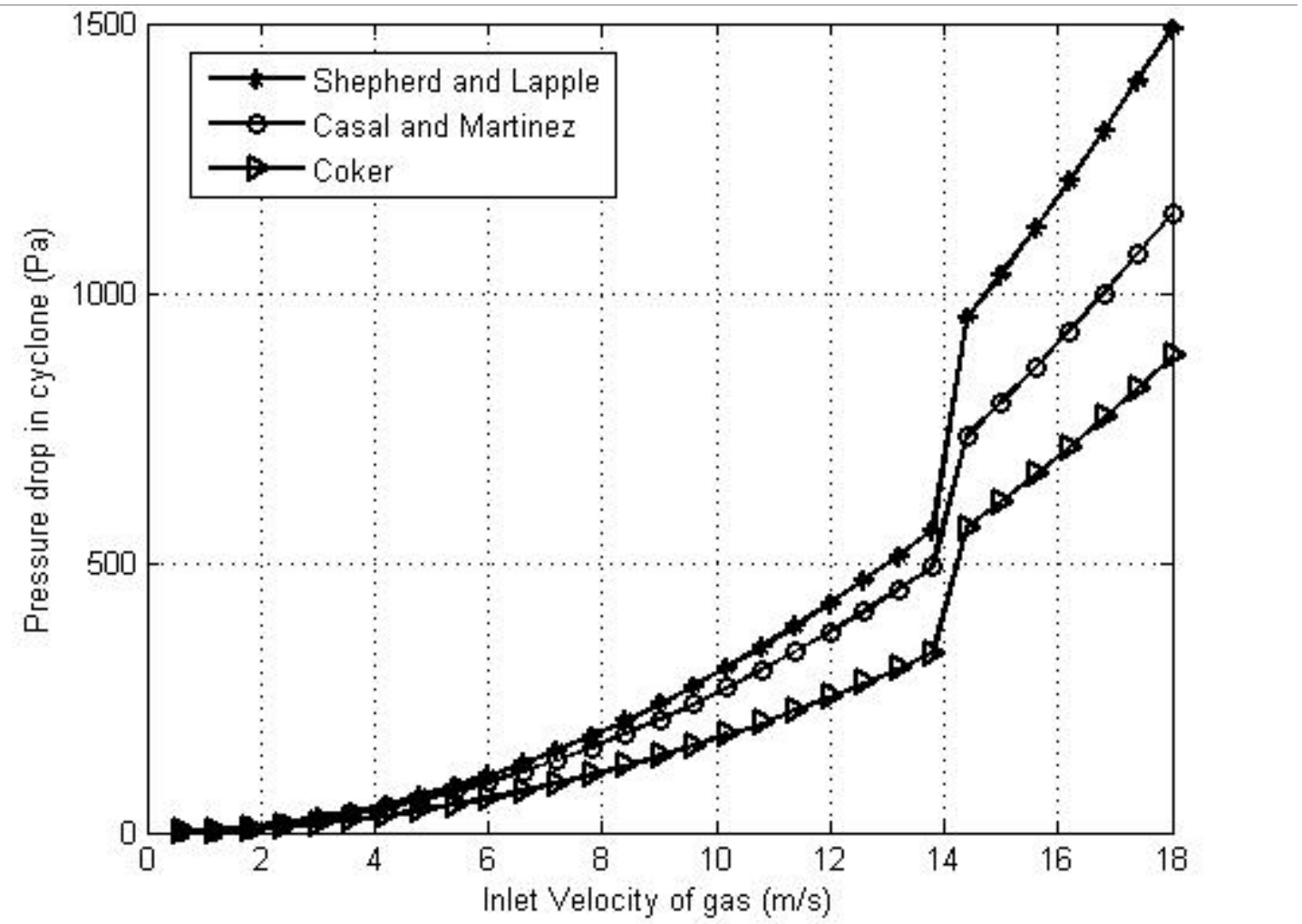

Figure 11. Pressure drop variation with biogas inlet velocity for three models.

In selecting or sizing a cyclonic separator for hydrogen sulfide and dust removal from biogas, trade-offs have to be made between geometric parameters, cyclone performance and collection efficiency, and minimum particle diameter and pressure drop. The 2D2D cyclone is observed to be the optimum design configuration based on the aforementioned criteria. Nevertheless, selection and sizing must be done based on the design specifications reflected in the design intent of the gas purification process. 


\section{CONCLUSIONS}

Gas cyclone separators are an economic and reasonably efficient devices for gas-solid separation. In purification of a $\mathrm{H}_{2} \mathrm{~S}$ and particle rich biofuel, oxygen in air is made to react with $\mathrm{H}_{2} \mathrm{~S}$ in the gas to produce elemental sulfur and water particles. Gas cyclones are often adopted for the separation process because they aid the reaction process by providing effective mixing of the reactants $\left(\mathrm{H}_{2} \mathrm{~S}\right.$ and $\left.\mathrm{O}_{2}\right)$ due to the centrifugal flow of the gases within the cyclone. Cyclones also cause the solid effluent of the reaction and dust particles to fall through the conic section of the cyclone. The proposed design presented in this work is based on a modification of the Texas A\&M Cyclone Design, where the modification fosters the reaction between $\mathrm{H}_{2} \mathrm{~S}$ and $\mathrm{O}_{2}$. This is achieved by adding an inlet duct for oxygen - in a manner that forces the incoming oxygen flow to be opposite to the flow of inlet biogas - in the conventional cyclone design. Based on the 1D2D, 2D2D and 1D3D configurations considered, an algorithm is prepared along with a graphic user interface designed on MATLAB for appropriate cyclone sizing, investigation of minimum particle diameter to be collected as well as pressure drop. A parametric analysis shows the effects of volumetric flow and velocity of the inlet gas on sizing of the cyclone, minimum diameter of solid particles collected and pressure drop. The 2D2D configuration is observed to be economic in terms of sizing (total height and diameter of cyclone) when compared with the other configurations. Also, the 1D2D configuration (which operates at the lowest inlet velocity compared to the other configurations) is observed to have the least pressure drop because pressure drop values are smaller at lower inlet velocities; the 2D2D configuration is also advantageous relative to the 1D3D considering pressure drop.

Empirical investigatons of the effects of oxygen quality and quantity on the chemical reaction and, indirectly, on the sizing and performance of the cyclones is needed. Such research is merited to help obtain a robust design for cyclonic separators in biofuel purification.

\section{REFERENCES}

Hoffmann, A.C. and Stein, L.E. (2002). Gas Cyclones and Swirl Tubes: Principles, Design and Operation. New York: Springer Science \& Business Media, pp. 277-334.

Shepherd, C.B. and Lapple, C.E. (1939). Air Pollution Control: A Design Approach In Cyclones, 2nd ed., D. C. Cooper and F. C. Alley, Eds., Illinois: Woveland Press Inc, pp. 127-139.

Galante, C.G., Pezzola, L., Priano, N., Scaramellini, S. and Sottocornola, A. (2012). Methane from biogas; the process, cleaning and projects. Semester Project, Department of Petroleum Engineering and Geophysics, Norwegian University of Science and Technology, Trondheim. pp. 1-20.

Pandya, D. (2010). A low cost micro scale scyclone separator design and computational fluid dynamics analysis. Masters Thesis, Aerospace Engineering, University of Texas at Arlington, pp. 1-63.

Ogedengbe, E.O.B. and Rosen, M.A. (2012). Electro-Kinetic Pumping with Slip Irreversibility in Heat Exchange of CSP-Powered Bio-Digester Assemblies. Entropy, vol. 14, pp. 2439-2455.

Kim, H.T., Lee, K.W. and Kuhlman, M.R. (2001). Exploratory design modifcations for enhancing cyclone performance. Journal of Aerosol Science, vol. 32, pp. 1135-1146.

Casal, J. and Martinez-Benet, J.M. (1983). A better way to calculate cyclone pressure drop. Chemical Engineering Progress, pp. 99-100.

Coker, J.K. (1993). Understand Cyclone Design. Chemical Engineering Progress, pp. 51-55.

Benitez, J.R. (1993). Process Engineering and Design for Air Pollution Control. Prentice Hall, pp. 334-339.

Kuo, K.Y. and Tsai, C.J. (2001). On the Theory of Particle Cutoff Diameter and Collection Efficiency of Cyclones. Aerosol and Air Quality Research, vol. 1, no. 1, pp. 47-56.

Park, K., Hong, C.H., Han, J.W., Kim, B.S., Park, C.S. and Kwon, O.K. (2012). The Effect of Cyclone Shape and Dust Collector on Gas-Solid Flow and Performance. World Academy of Science, Engineering and Technology, vol. 6, pp. 217-222.

Svarovsky, L. (2014). Gas Cyclones," FPS Institute. Available: http://www.svarovsky.org/fps2/GASCYC.pdf. [Accessed April 2014].

Wang, L. (2004). Theoretical Study of Cyclone Design. Doctoral Dissertation, Biological and Agricultural Engineering, Texas A \& $M$ University, pp. 1-136.

Wang, L., Buser, M.D., Parnell, C.B. and Shaw, B.W. (2003). Effect of air density on cyclone performance and system design. American Society of Agricultural Engineers, vol. 46, no. 4, pp. 1193-1201.

Fodora, M., Gadus, J., Marecek, J. and Vitez, T. (2013). Design of Laboratory Cyclone Separator for Biogas Purification. Acta Universitatis Agriculturae Et Silviculturae Mendelianae Brunensis, vol. 61, no. 3, pp. 631-635.

National Programme Technology Enhanced Learning (NPTEL). (2015). Separation Equipments: General Design considerations of cyclone separators, centrifuges, separation equipments. Available: nptel.ac.in/courses/103103027/21. [Accessed 1 May 2015]. 
Babarinsa, O., Ogedengbe, E.O.B. and Rosen, M.A. (2014). Mixing Performance of a Suspended Stirrer for Homogenizing Biodegradable Food Waste from Eatery Centers. Sustainability, vol. 6, pp. 5555-5565.

Funk, P.A. and Baker, K.D. (2013). Engineering and Ginning: Dust Cyclone Technology - A Literature Review. The Journal of Cotton Science, vol. 17, pp. 40-51.

Urja Bio-Systems. 2015). Get the power of Biogas and Biomass from Experts. Urja Bio-Systems. Available: www.urjabiosystems.com/about_links. [Accessed 13 May 2015].

Nazaroff, W.W., Alvarez-Cohen, L., Mihelcic, J.R. and Zimmerman, J.B. (2013). Gaseous Emission-Control

Technologies $\quad$ Technology).
http://engineering.dartmouth.edu/ $\sim$ d30345d/courses/engs37/. [Accessed 29 April 2015]. 